\title{
Rem Koolhaas and Álvaro Siza in Asia: An Architectural Comparison
}

\author{
By Shuenn-Ren Liou*
}

\begin{abstract}
Rem Koolhaas (1944- ) and Álvaro Siza (1933- ) are two of the most significant living architects in contemporary architecture. They have been devoted to architectural creation for a long period of time and produced a great number of works of high quality and originality. It is not surprising that Koolhaas and Siza came to Asia for architectural practice in 2002 and 2005, respectively. In the past few decades, research on Koolhaas' and Siza's architectural works mainly focused on their works in Europe and America. Although there were some individual reports on Koolhaas' and Siza's activities and works in Asia, they lacked of systematic investigation and analysis, not to mention cross region comparisons. Being highly respected, the modification and/or transformation of their design ideas, thinking, processing, and making, i.e. their architectural strategies including design strategies and management strategies for Asian cultures and regions constitute important sources for exploration in the architectural history and theory. After the investigation on Siza's architectural works in Asia (Liou, 2012, 2013, 2014a, 2014b), the present study attempts to extend the accumulated experiences and analyse the work of Koolhaas as a case subject, and furthermore to conduct comparative analysis on the style and design of the two architects. Specifically, in this paper, Koolhaas' design strategies and management strategies for his Asian architectural works are studied. His design strategies include OMA's design process, public urban space, architectural typology (high-rise building and theater), skin material, and plane material. The management strategies consist of OMA's partnership, network of international collaboration and Asian strategy. Finally, the design strategies and management strategies of Koolhaas' and Siza's are compared. It might be argued that the architectural strategies employed by Koolhaas and Siza constitute the two ends of the spectrum for those western architects who came to Asia for practice; some architects like Zaha Hadid and MVRDV are closer to Koolhaas and some like Vittorio Gregotti and Steven Holl are closer to Siza.
\end{abstract}

Keywords: Rem Koolhaas, Álvaro Siza, Asian Architecture, Design Strategy, Management Strategy

\section{Introduction}

After the investigation on Siza's architectural works in Asia (Liou, 2012, 2013, 2014a, 2014b), the present study attempts to extend the accumulated experiences, taking Koolhaas as the subject for study. Furthermore, a comparison analysis between the two architects is conducted. Siza's past architectural creation in Asia serves as the background for discussion and seven of his representative works were selected as subjects for study; namely, the following: AnYang Pavilion (2006), Mimesis Museum (2009), Amore Pacific

*Professor, National Chen Kung University, Taiwan. 
R\&D Center (2010), and Jeju House (2010) in Korea; Niki Hotel \& Spa Arasaki (2008-) in Japan; TaiFong Golf Club House (2009-) in Taiwan; ShihLien Chemical Office Building (2014) in China.

In general, Siza's architectural works in Asia could be seen as a continuum of his works in Europe. The seven works reveal the common character of Siza's design thinking, methods, and ways of handling construction and materials, e.g. the delicate arrangements of the simple geometric volumes under various conditions of sites, the ingenious introduction of natural light to interior space and the minimalist attitude to the use of materials and joints. Five emerging issues critical to Siza's architectural creation in Asia are identified and analyzed in depth, including the evolution of geometry, the application of open space, the manipulation of $\mathrm{V}$-shaped space, the typology for natural light and the tectonics (Liou, 2014b). Finally, Siza's international collaborations for his Asian works are examined (Liou, 2014a).

From the perspective of the overall performance, Siza's architectural works in Asia in fact are not different than his works in Europe. It seems difficult to illustrate how Siza might have established a new strategy, thus, producing apparently distinguishable features when confronted with the Asian culture and environment. Nevertheless, it is noted that the expression of the formal composition dominated by curved lines appears stronger in Asia. This might be attributed to the trust of the clients as well as the close cooperation with the local experts (Liou, 2014b:100). It was observed that Siza acquired a freer space for creation in Korea and China, especially in his latest work, Shihlien Chemical Office Building in China, which showed an unprecedented expression in curved spatial form (Liou, 2014a:65-70).

In the present paper, Koolhaas' design strategies and management strategies for his Asian architectural works are analyzed. The design strategies include OMA's design process, public urban space, architectural typology (high-rise building and theater), skin material, and plane material. The management strategies consist of OMA's partnership, network of international collaboration, and Asian strategy. Finally, the design strategies and management strategies of Koolhaas and Siza are juxtaposed and compared.

\section{Koolhaas' Design Strategies for his Asian Architectural Works}

Koolhaas' design strategies are identified through an analysis on four of his architectural works in Asia: CCTV Headquarters (Beijing, China, 2002), Seoul National University Museum of Arts (Seoul, South Korea, 2005), Taipei Performing Arts Center (Taipei, Taiwan, 2009) and Shenzhen Stock Exchange (Shengzhen, China, 2013). The strategies could be depicted in five ways as follows:

\section{OMA's Design Process and Turning Points}

In general, OMA's design process could be divided into three stages and eight steps. The three stages are "Competition," "Modification" and "Detailed 
Design." In the stage of competition, three steps are involved. The first step entails a critical study on relevant architectural precedents. It includes OMA's previous projects and notable cases in architectural history (Jin, 2012:46). The second step is Koolhaas' decision making. An investigation on OMA's partnership reveals that the composition of partners in Koolhaas' office had been constantly changing since 2006. Therefore, Koolhaas' influence on the recap of the concepts, typology, and experiments on material in previous projects appears clear as well as crucial. The third step is the collaboration with international experts. OMA's unique architectural design often required technical feedback and validation during the design process. The structure engineering firm ARUP, for example, normally joined OMA at the stage of competition. dUCKS Sceno specializing in stage design and DHV specializing in acoustics were invited to join the international competition for the construction of Taipei Performing Arts Center (OMA, 2009).

The second stage is the modification which includes the steps of client's feedback, landscape design, and collaboration with local teams. The stage of modification followed after OMA managed to win many competitions. Modification mainly came from client's requests. For example, Taipei city government decided to remove the night market on the ground floor from the program of Taipei Performing Arts Center. The relative height of the tower and the base of Shenzhen Stock Exchange were also adjusted after competition. In three of the Asian works of OMA, acquired through competition, the detailed landscape design was carried out by its long-term collaborator Inside Outside. The Chinese paper-cutting pattern was applied in the sky garden of Shenzhen Stock Exchange. Besides the collaboration with local architects, OMA worked closely with other local industry teams to fulfill the special needs of the projects.

The third stage is detailed design, including the steps of interior design and material study. The interior design of Taipei Performing Arts Center dealt with complicated issues of auditorium, stage, and flexible partition. The study on color played an important role in the design of office spaces in CCTV Headquarters and Shenzhen Stock Exchange. The application of various textures enhanced the spatial guidance in Seoul National University Museum of Arts (Yoshida, 2006:48).

\section{Public Urban Space}

"Public Level" and "Public Circulation" designs were both implemented by OMA to create certain public urban space in their urban projects. The public urban space could be embedded in two kinds of buildings: (1) the buildings for public use, and (2) the buildings for non-public use. Seattle Central Library is a good example of public, urban space design, interweaving the five relatively stable and private platforms (parking, staff, meeting, stacks, headquarters) with four fluid, public spaces (playgrounds, living rooms, mixing chambers, reading rooms) and thus, successfully creating a new type of urban public library (OMA, 2004). As for the public urban space in the buildings for non-public use, OMA skillfully combined the "Public Level" and the "Public Circulation" 
designs to release the public space of the building. As shown in Figure 1, the public levels consisted of the ground, the middle, and the top levels. The public urban space could be utilised as an open lobby, outdoor space, or bridge on the ground level,; sky lobby, sky deck, or sky plaza on the middle level; roof lobby or roof terrace on the top level. The public circulation consisted of an internal public loop, an external urban passage as well as external connection to urban infrastructure.

Figure 1. The Strategy for the Creation of the Public Urban Space in the Buildings for Non-Public Use

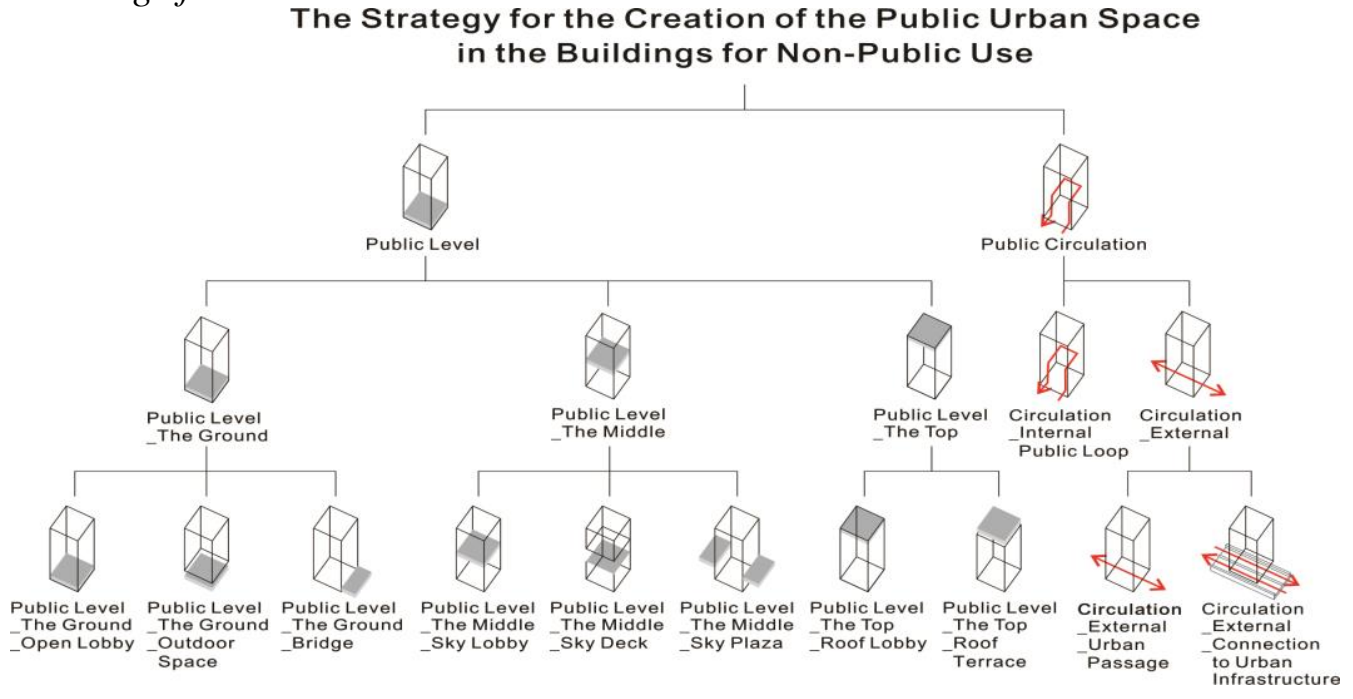

OMA's Study on Architectural Typology

For OMA's projects in Asia, there are two approaches taken on architectural typology. The first approach is the subversion on high-rise building type, characterized by the experiment of the morphology of high-rise building and the operation on tower and base in high-rise buildings. The second approach is the continuity and variation in theater building types, characterized by the insertion of the tiered auditorium and the adjustable theater.

(1) The subversion on high-rise building type:

As shown in Figure 2, there were totally 30 high-rise projects designed by OMA between 1991 and 2014. They could be categorized into 7 types: shift, twist, step, lean, convex, concave and others. It should be noted that OMA did not participate in any high-rise architectural competition in Asia until 1996. The number of the projects in Asia was 15 which accounted for half of the total number of OMA's high-rise projects. Among the 30 projects, 24 were not eventually built (Stamp, 2012). Moreover, among the 6 high-rise projects which were built, 5 of them were in Asia, 4 of them were in China and one in Thailand. The only built high-rise project outside Asia was located in the Netherlands. As for the case of "tower and base" designs in high-rise building, 15 of the 30 projects including such designs are analyzed. As it can be seen in Figure 3, there were three basic types: 
single tower plus single base, multiple tower plus single base and twin towers plus twin bases. The type of single tower plus single base could be divided into two sub-types: the one with base on the ground level and the other with the base rising to the middle level. The former could be further developed into 4 sub-types depending on the spatial relation between the tower and the base. Similarly, the type of multiple tower plus single base could be divided into the sub-types of base on the ground level and base rising to the middle level. CCTV Headquarters fall into the category of twin towers plus twin bases.

Figure 2. The Typology of OMA's High-Rise Buildings

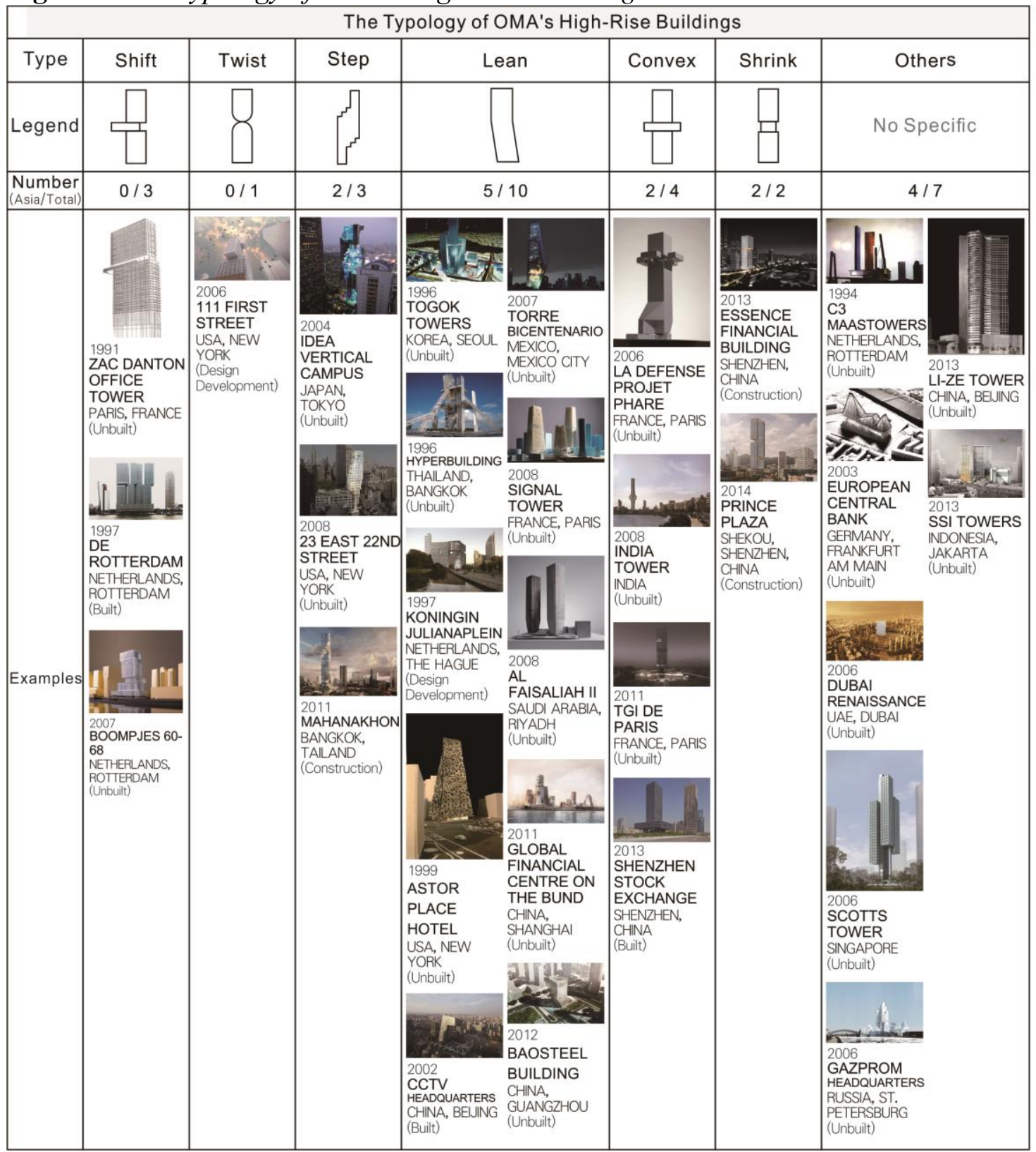


Figure 3. The Combination of Tower and Base in High-Rise Building Type

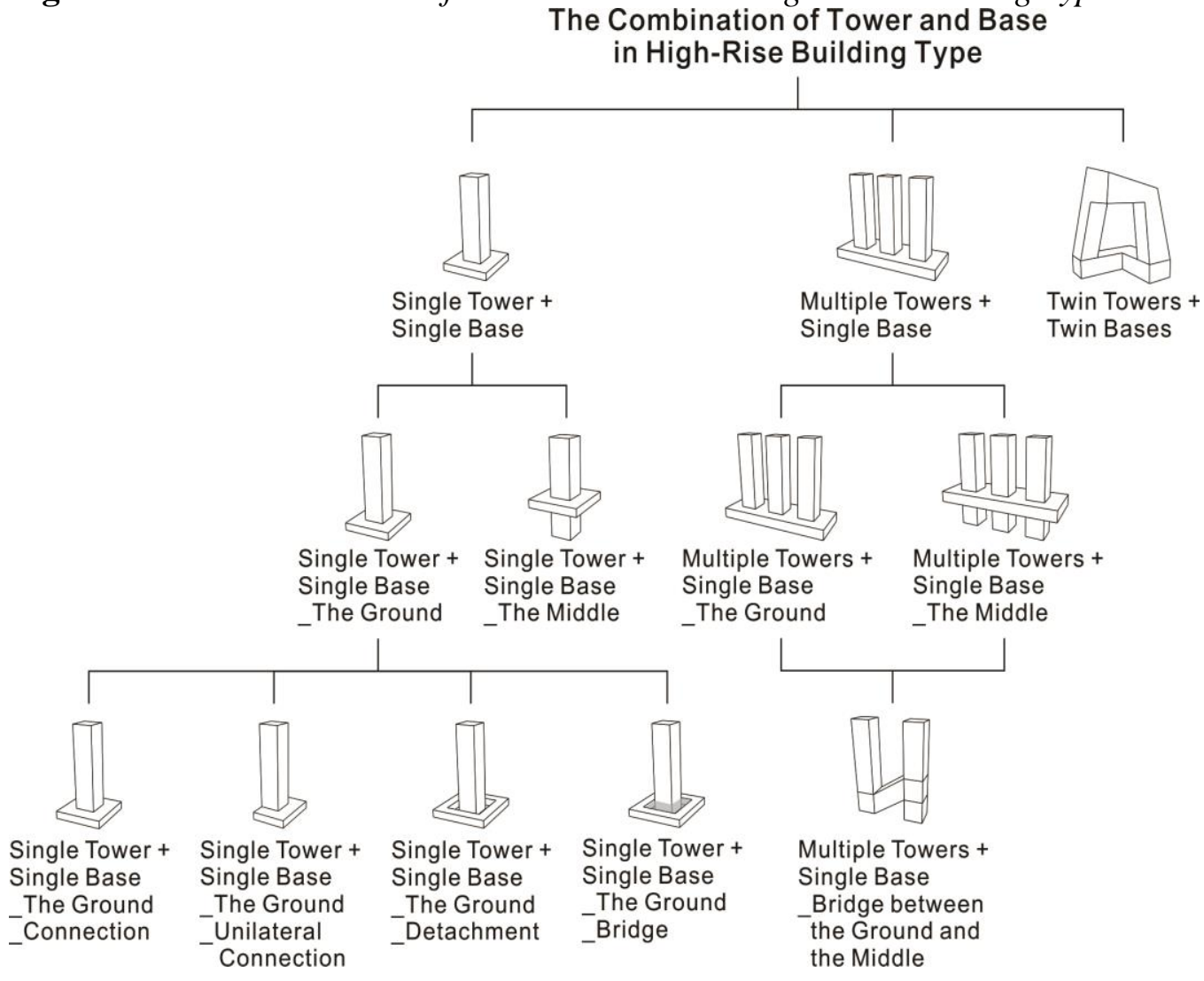

(2) The continuity and variation in theater building type:

The analysis of the 7 theater projects conducted between 1994 and 2009 reveals that the insertion of tiered auditorium was continuously applied by OMA in the design of theater building type. As shown in Figure 4, the form of the auditorium could be wedge-shaped or curved. The curved auditorium was P-shaped at the beginning to, first, change to $\mathrm{S}$-shaped as in Guangzhou Opera House in 2002, and finally evolve to spherical as in Taipei Performing Arts Center in 2009. The auditorium could be adjacent to the bottom or the end of the elongated body while it could even extend laterally. As for the design of adjustable theaters, it was mainly achieved through 2 modes of operation: through horizontal elements (floors and seats) lifting and moving and through vertical elements (walls and scenery) opening, closing, and rotating. The theater design in Taipei Performing Arts Center (2009) was actually an application of the idea of lifting floors and movable seats, at first being implemented in Dee and Charles Wyly Theater in 2004. Furthermore, it took Zimmermann's "Die Soldaten" as a simulation on opera to create a super theater with a stage of 100 meters in length (OMA, 2009). 
Figure 4. The Theater Buildings with the Insertion of Tiered Auditorium Designed by OMA between 1994 and 2009

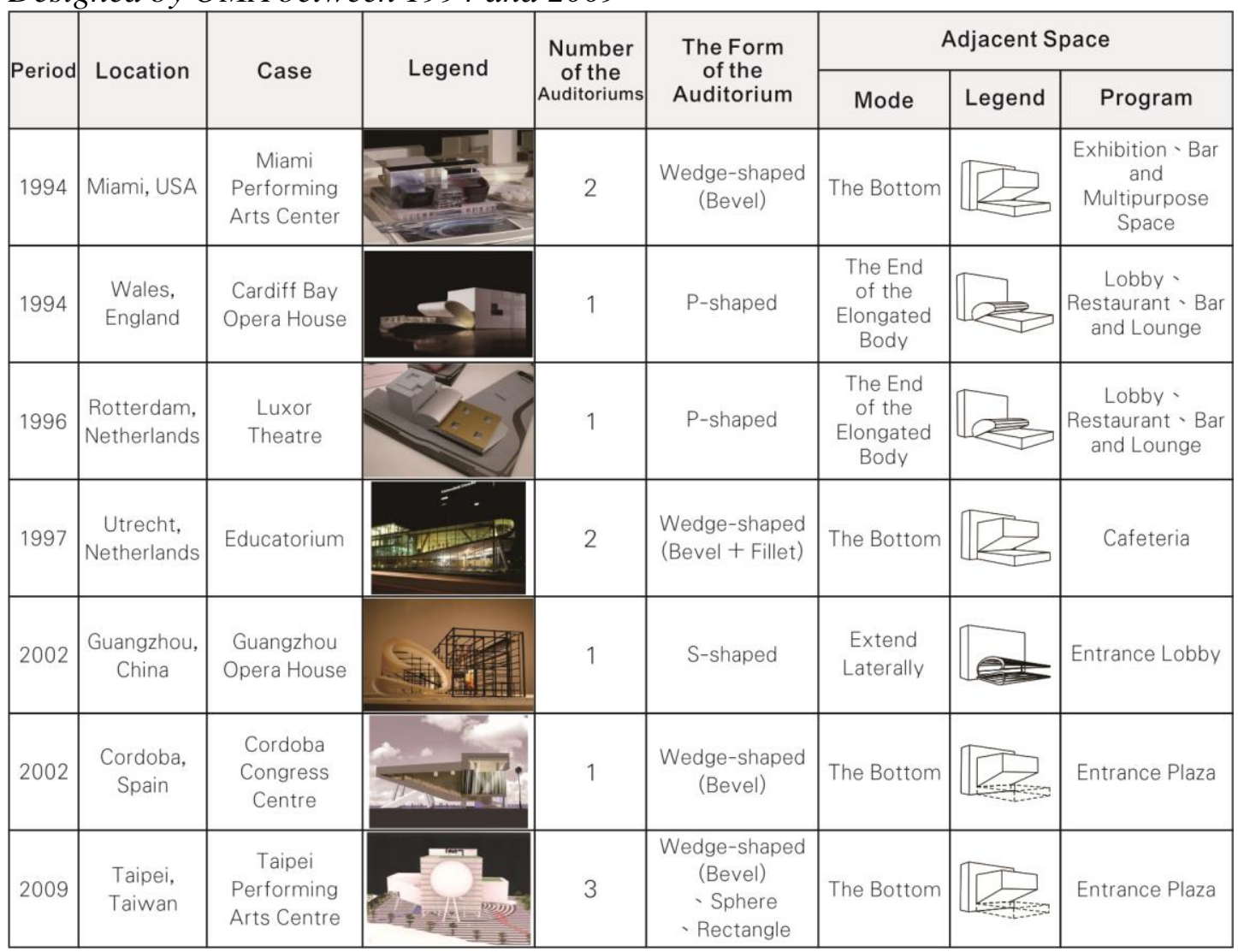

\section{Skin Material}

OMA's building skin was expressed through the application of various materials such as metal, membrane and glass in addition to reinforced concrete. The diligent application of metal could probably be traced back to Prada San Francisco in 2000. Within this context, homogeneous circular openings were used to create the pattern on the building façade. Moreover, 6 types of metal pipe sections were combined and arranged to generate the visual diversity on the building façade of Dee and Charles Wyly Theater in Dallas. Membrane was applied to the projects of Serpentine Gallery (2006), Prada Transformer (2008), 7 Screen Pavilion (2012) and National Museum of China (2011). Lastly, the application of glass skin was significant in 3 of Koolhaas' Asian architectural works. Seoul National University Museum of Arts and Shenzhen Stock Exchange used flat glass and Taipei Performing Arts Center used threedimensional glass. The three-dimensional glass first appeared in C-shape in Porto Casa da Musica (2005). It was further developed into S-shaped and it was applied in Taipei Performing Arts Center (2009) (Jin, 2012: 51). OMA's study and application of glass in building skin is shown in Figure 5. 
Figure 5. OMA's Study and Application of Glass in Building Skin

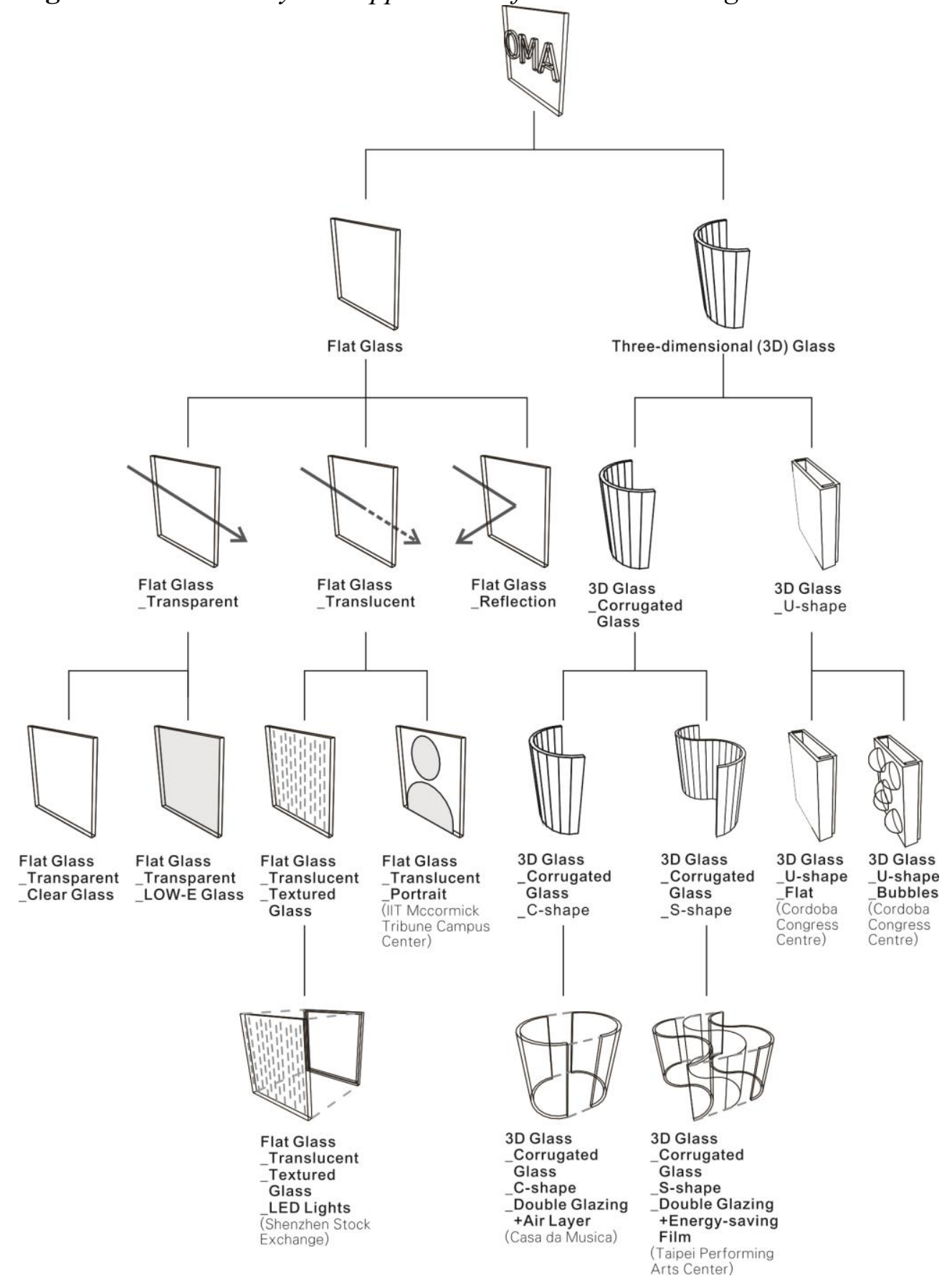

\section{Plane Material}

The systematic study and application of materials appears to play an important role in Koolhaas' design strategies for his Asian architectural works. As it can be seen in Figure 6, the system for the application of materials can be divided into three parts: the pavement, the wall, and the ceiling plus pavement. The material of pavement was applied to enhance the transition of interior and exterior spaces as well as the horizontal flow and stop. The material of wall 
was used to interpret the horizontal and vertical flows in space while the ceiling plus pavement material was used to enrich the horizontal flow and stay.

Figure 6. OMA's System for the Application of Material

OMA's System for the Application of Material

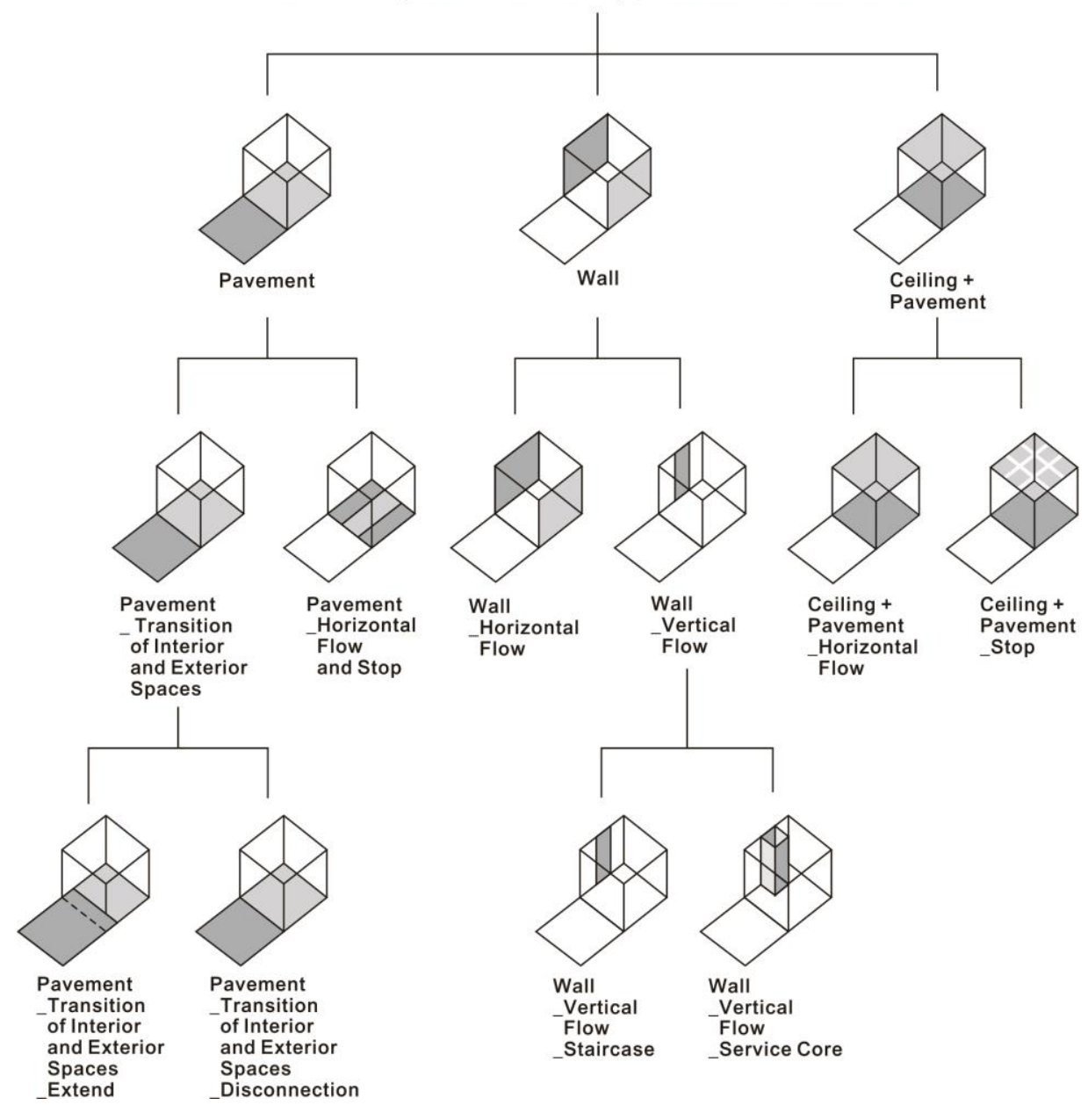

\section{Koolhaas' Management Strategies for His Asian Architectural Works}

Koolhaas' management strategies are explored through 3 directions: the "partnership" for OMA's internal operation, the "teamwork" for international collaboration and the "Asian strategy" for OMA's architectural projects in Asia. On "partnership", the average number of partners was 6 to 7 from 2006 to 2014. Among the total number of 10 partners during this period of time, Rem Koolhaas, Ellen van Loon and Reinier de Graaf (in charge of AMO) were the only ones involved in stable partnership since 2006. Ole Scheeren was first engaged in the partnership scheme in 2006 when OMA established its office in Beijing for the construction of CCTV Headquarters. David Gianotten entered partnership in 2009 when OMA won the competition of Taipei Performing Arts Center and established its office in Hong Kong. In 2013, the Syrian-born Iyad 
Alsaka also joined the partnership, being in charge of the project in the MiddleEast and South Africa. In all the architectural works in Asia, Koolhaas was the key partner, involved from the very first stage of competition.

Regarding "teamwork", 4 international consulting firms were involved in the collaboration with OMA; namely, Inside-Outside (NL) dealing with exterior landscape and interior design, dUCK sceno (France) dealing with stage and scenery design, DHV (NL) dealing with acoustics design and Arup (UK) dealing with structure design. These four firms all participated in CCTV Headquarters and Taipei Performing Arts Center construction. In particular, Inside Outside and Arup participated in all four OMA's architectural works in Asia.

Regarding "Asian strategy", it should be noted that OMA's activities in Asia could be divided into four periods. The first period was from 1991 to 1998. The major activities were in Japan and South Korea, and no building was constructed during that first period of OMA's enter in the Asian market. The second period extended from 2002 to 2008. During that period, OMA entered China's market through CCTV Headquarters while, at the same time, its activities in Japan and South Korea continued. The third period started in 2009 and ended in 2011. During this period, in addition to Taipei Performing Arts Center (Taiwan) and Interlace (Singapore), OMA's projects in Asia were mainly conducted in China and Hong Kong. The fourth period was from 2012 to 2013. Though still active in China and Hong Kong, OMA received four projects from Indonesia and Australia in 2012, indicating its tendency of moving southward. Up to the end of 2012, the total number of people working in OMA's offices in Asia exceeded 100 (Jin, 2012:31). In 2013, OMA won the competition of Airport City in Qatar. An office in Doha was established afterwards. Finally, Koolhaas' research also reflects his interest and ideas in Asian cities and architecture. The "S, M, L, XL" published in 1995 reveals Koolhaas' concerns regarding Singapore (Koolhaas and Mau, 1995). In 1996, Koolhaas took a group of GSD students to the region of Pearl River Delta in China for field investigation. The outcome of the investigation became a book called "The Great Leap Forward", published in 2002 (Koolhaas, 2001). Furthermore, Koolhaas undertook a study in 2005 on the Metabolist Movement in Japan, turning out to be the book of "Project Japan" (Koolhaas and Obrist, 2011).

\section{Comparison of Koolhaas' and Siza's Architectural Strategies in Asia}

\section{Passive v.s. Active Extension}

Siza's activities in Asia started from South Korea and then, expanded to Japan, Taiwan, and China. All of the projects such as Private Houses, Museums, R\&D Centers, Hotels, Club Houses, and Industry Headquarters were acquired through clients' invitations. Thus, the extension of Siza's architectural career from Europe was passive. On the contrary, most of OMA's projects in Asia were acquired through international competition. Koolhaas' 
activities in Asia could be traced back to 1991. At first, he started working in Japan, South Korea, China, Hong Kong and Taiwan to recently move towards the southeast part of Asia and Mid-East. This expansion indicates Koolhaas' proactive attitude and thoughtful strategy for extension in Asia.

\section{International Collaboration}

Siza's architectural projects in Asia were conducted through the triangular pattern of collaboration between Siza, clients, and local architects, as shown in the upper part of Figure 7. The design development was led by Siza. Furthermore, Siza's associate architect Carlos Castanheira, the clients' manager, and the contractor worked closely to resolve the various problems (Liou, 2014a:48). Koolhaas' practice in Asia also maintained a triangular pattern similar to Siza, as shown in the lower part of Figure 7. Nevertheless, OMA's international collaboration normally began at the stage of competition. After winning the competition, the international team would continue to work on the stages of modification and detailed design. In Koolhaas' architectural works in Asia, the international team covered four areas of specialty: (1) Structure Design by Arup (UK), (2) Exterior Landscape and Interior Design by Inside Outside (NL), (3) Acoustics Design by DHV (NL), (4) Stage and Scenery Design by dUCKS sceno (France). The combination of the collaborative partners would then be adjusted to satisfy the needs of the competition program. 
Figure 7. Siza's and Koolhaas's Patterns of International Collaboration

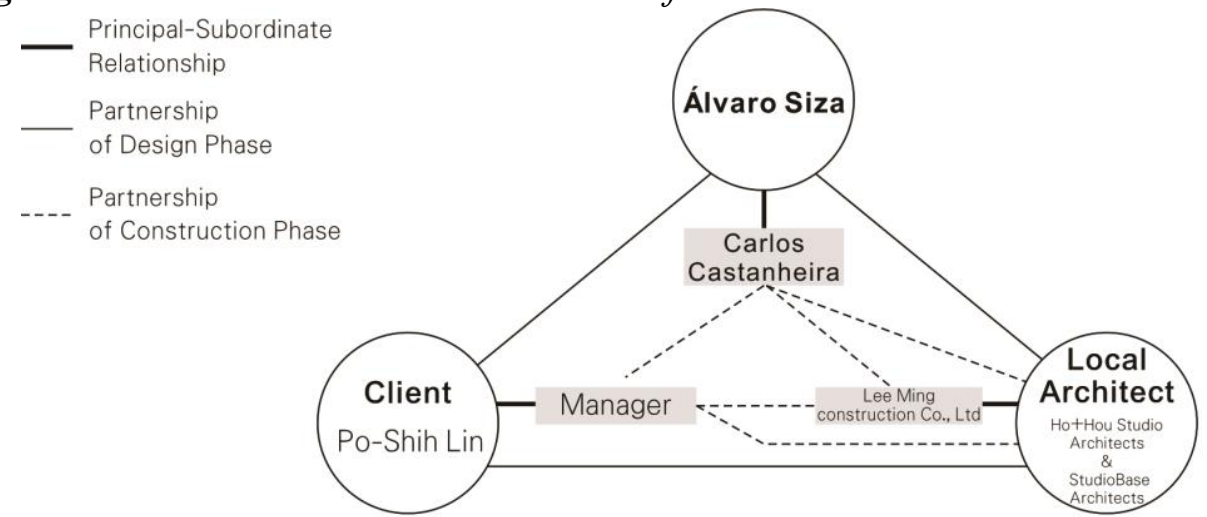

Siza's Model of International Collaboration as in the project of TaiFong Golf Club House.

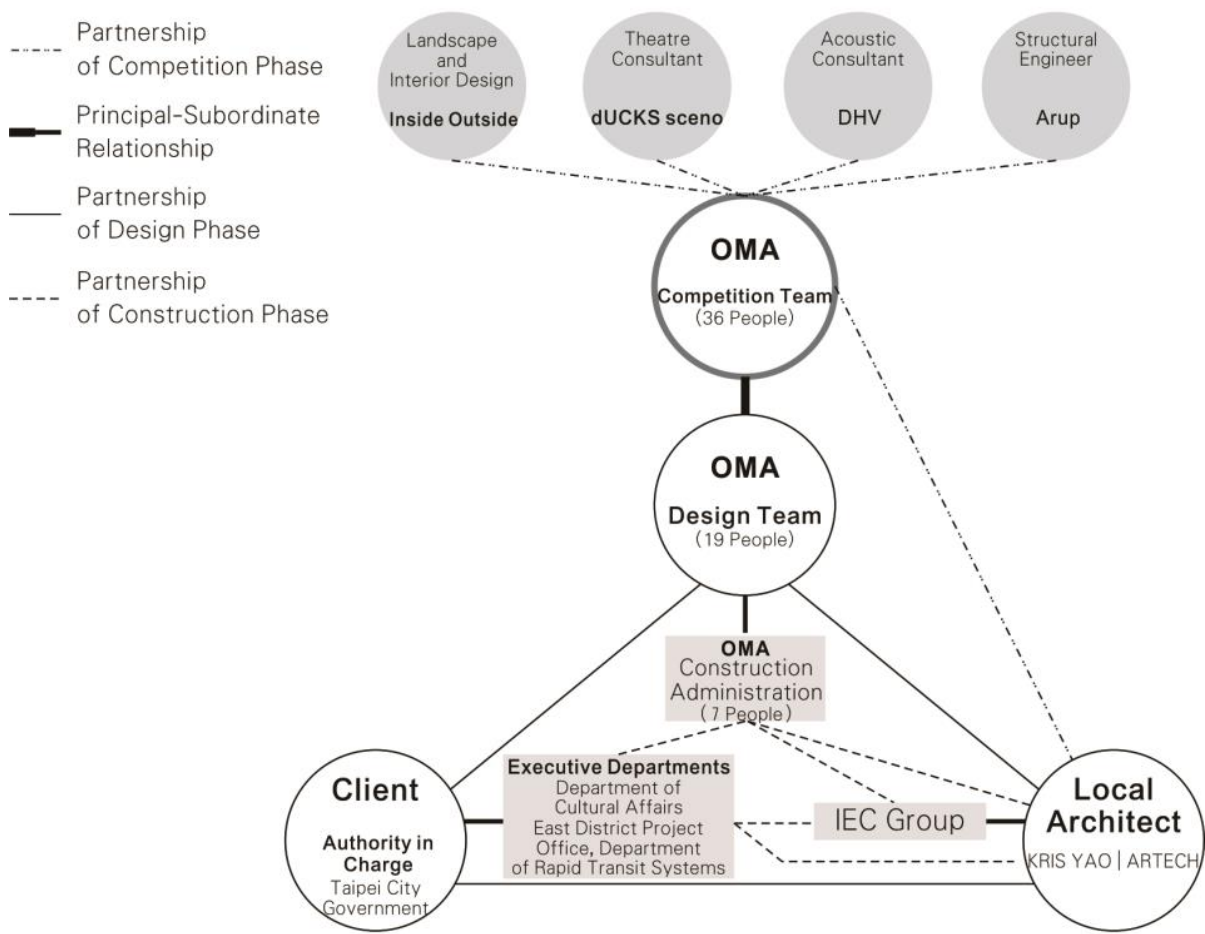

Koolhaas' Model of International Collaboration as in the project of Taipei Performing Arts Center.

\section{Design Process and Design Tools}

With respect to the design process, Siza's overall site plan was often established at the very beginning And then, followed by architectural design, interior design, and detailed design. The design process was thus arguably rather linear and one-directional than iterated for big change (Liou, 2014a:4547 ), as shown in the upper part of Figure 8. Koolhaas' design process contained more cycling processes of modification, as shown in the lower part of Figure 8. For example, he went through the process of site plan, architectural design, and 
interior design at the stage of competition. He would also probably undertake another cycling process due to the feedback from clients.

Figure 8. The Comparison of Siza's and Koolhaas'Design Processes

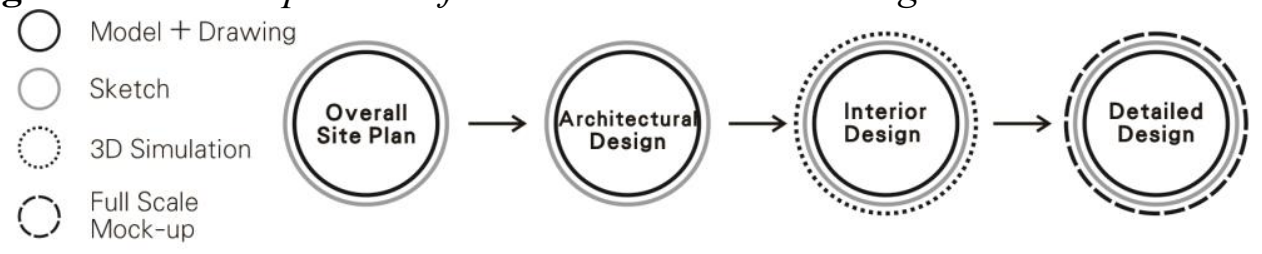

Siza's Design Process
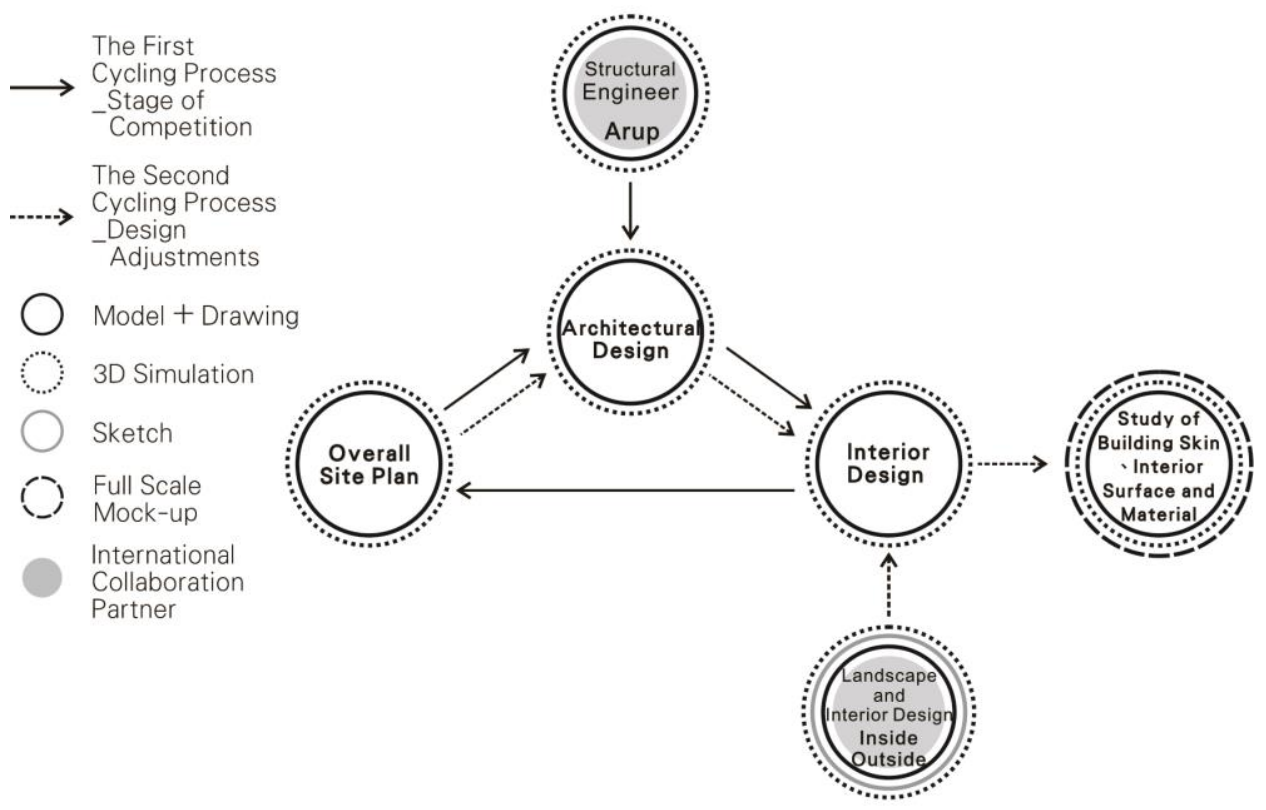

Koolhaas' Design Process

Siza used sketch, models, and drawing in the process of design development, as well as 3D simulations at the stage of interior design. Full scale mock-up models were often employed by Siza to establish communication with the contractor. As to Koolhaas, 3D software, model, and drawing were commonly used in the design process. For the collaboration with Arup, 3D modeling was used for the evaluation of structure performance. For the collaboration with Inside Outside, sketch was added and full scale Mock-up models were employed for the study of interior surfaces and materials.

\section{Structure}

Siza and Koolhaas took different approaches regarding structure. In Siza's works, the edge lines of columns and beams were often hidden intentionally, and in certain special spaces (e.g. the reception area in Taifong Golf Club House), diameters were minimized, after discussing with the engineer, to 
achieve Siza's aesthetic quality (Liou, 2014a:58). On the contrary, starting from the project of Bibliothèque de France in 1989, the huge truss system was not only used as façade pattern, but had also become an idiomatic element/symbol in OMA's subsequent projects. It was followed by the application of transparent and semi-transparent materials to the enclosure of the truss system, as shown in Seoul National University Museum of Arts. OMA's concern on structure was not limited to the skeleton of the building but also extended to the structure of the skin itself. The S-shaped 3D glass applied in Taipei Performing Arts Center could be regarded as an evolution from the Cshaped 3D glass applied in Porto Casa da Musica in 2005, as shown in Figure 5 .

\section{Construction and Material}

In his Asian projects, Siza would first gain an understanding of the local construction and materials based on Carlos Castanheira's investigation. This analysis constituted the fundamental reference for Siza's architectural design later on. It was noted that the designs of doors and windows as well as some architectural details were extended from Siza's previous design. The metallic materials such as door handles, hinges were imported from Portugal (Liou, 2014b:98-99). OMA's construction plan appeared in the early stage of design when collaborating with Arup. It was modified and executed through the participation of local architects and contractors in the latter stages. OMA's approach to the study and application of material was proactive. It was reflected in the attempt to find a better solution to the problem of local geology and climate (e.g. the S-shaped glass was improved for earthquake and typhoon in Taipei Performing Arts Center) (Jin, 2012:51) and in the design strategy for local culture and industries. Quite representative examples are the Chinese cultural elements used in the interior design for CCTV and the patterned glass developed by the joint venture with international and Chinese industries and applied in Shenzhen Stock Exchange) (Jin, 2012:148).

\section{Discussion and Conclusions}

Rem Koolhaas and Álvaro Siza are two of the most significant living architects in contemporary architecture. On the basis of the analysis of Siza's architectural works in Asia, this study focused on the work of Koolhaas and also conducted a comparative analysis between the two architects.

It could be argued that Koolhaas took a theory-based approach in his architectural practice. Through the analysis of the projects undertaken by Koolhaas, it was proven that the idea of architectural typology was dialectically applied in his architectural works in Asia. "High-rise building" turned out to be one of the most important topics for Koolhaas when confronted to the Asian challenges. As a matter of fact, CCTV Headquarters was Koolhaas' stepping stone into Asia; however, its root of creation could be traced back to the prototypical concept of "the globe and the needle" in his book under the title 
"Delirious New York" (Koolhaas, 1978), published in 1978. Moreover, the representative high-rise buildings around the world were taken as objects of reference and criticism, and following that, a deep subversive proposal on high-rise building was developed. On the contrary, Siza was a "do-more-talkless" practitioner. For Siza, there was no particular theory supporting any practice and architectural design had to come back to investigate the essential human experience, as well as the relationship between architecture and the natural environment. Consequently, on architectural typology, Siza tended to use "open space" as the key element for spatial organization, thus, operating deliberately on the alternate use of courtyards, terraces and patios (Liou, 2014b:86-89). At the same time, in his architectural works in Asia, Siza made a bolder expression in geometric forms and a more comprehensive expression in natural lighting, in response to the local conditions and limitations of the environment of site. Particularly noteworthy are Siza's applications of curvilinear forms in ShihLien Chemical Office Building and lighting by water in Jeju House and TaiFong Golf Club House (Liou, 2014b:99-100).

In addition, coming to Asia, Koolhaas and Siza employed relatively different attitudes and approaches in dealing with the issue of cross cultural differences. Following the projects in China, OMA continually acquired architectural projects in Indonesia, Malaysia and Vietnam. As a result, OMA's Asian Headquarters in Hong Kong kept recruiting new blood. The number of people working in the office was 12 in 2009 and reached 60 in 2012. Among them, Chinese designers maintained a share of more than 60\% (Jin, 2012:19). The Chinese community and the international environment in Hong Kong made it easier to achieve this goal of recruitment. With respect to the expression of design, Koolhaas adopted directly the elements of ornamentation from the Oriental and Chinese culture and used them as the foundation for the composition of garden landscapes and interior designs. Moreover, research teams were organized in OMA to explore the various possibilities of expression in materials and colors. There were no significant changes in Siza's architectural strategies since 2005. The design strategies and management strategies applied in South Korea, Japan, and Taiwan were similar; nonetheless, due to the gaps of the interfaces in the construction process and the problems of rapid production in China, Siza had to make some adjustments and changes in this process, in order to reach the consistent quality of his architectural works (Liou, 2014a:55). In general, unlike Koolhaas, it was observed that Siza's interpretation of regional culture had been rarely affected by external factors including the impact of local architects and collaborative teams. The overall creation was mainly came from his personal experience and comprehensive judgment. One could hardly see any representational and cultural elements in Siza's architectural works in Asia. Nevertheless, through the examination of site planning, spatial organization, and form-making, Siza's works were always able to accurately grasp the special conditions of the local environment and reflect the necessity and relevance of the architectural design.

Koolhaas and Siza could be regarded as two typical models of the known western architects coming to Asia. They represented the two extremes. It might 
be argued that many architects from Europe and America seeking to develop in Asia could find their locations of reference between the two ends of the spectrum pulled up by Koolhaas and Siza. Some architects like Zaha Hadid and MVRDV are closer to Koolhaas and some like Vittorio Gregotti and Steven Holl are closer to Siza. In the present paper, a number of emerging issues in the spectrum were explored through the preliminary analysis and comparison of the architectural strategies employed by Koolhaas and Siza. The present study's main aspiration is that the contrasts and differences derived from the above comparative analysis will contribute in the identification of the challenges faced by international architects coming to Asia for creation and practice. Finally, it is suggested that further studies should be done to gradually increase our understanding on the impact of globalization on contemporary Asian architecture and urbanism.

\section{Acknowledgments}

This research was granted by Ministry of Science and Technology (MOST 102-2221-E-006-227-) of Taiwan.

\section{References}

Jin, L. 2012. Architectural Creation 162: OMA Asia: Programmatic and Dynamic Reconfiguration of Cities. Beijing Institute of Architectural Design, Beijing.

Koolhaas, R. 1978. Delirious New York: A Retroactive Manifesto for Manhattan. Monacelli Press, New York.

Koolhaas, R. (Ed.) 2001. Great Leap Forward. Taschen, Koln.

Koolhaas, R. and Mau, B. 1995. Small, medium, large, extra-large: Office for Metropolitan Architecture. Monacelli Press, New York.

Koolhaas, R. and Obrist, H. 2011. Project Japan : Metabolism Talks....Taschen, Cologne.

Liou, S.-R. 2012. A Preliminary Study on Álvaro Siza's Architectural Works in Asia. Technical Report. National Science Council, Taiwan. (NSC 100-2221-E-029-029)

Liou, S.-R. 2013. A Case Study on Álvaro Siza's Architectural Works in Asia. Technical Report. National Science Council, Taiwan. (NSC 101-2221-E-006-280)

Liou, S.-R. 2014a. Álvaro Siza in Asia. Studio MORPHOLOGY X PROTOTYPE, Tainan.

Liou, S.-R. 2014b. An Analysis and Comparison on Álvaro Siza's Architectural Works in Asia. Journal of Architecture, 88 (June, 2014), 79-104.

OMA 2004. SEATTLE CENTRAL LIBRARY http://www.oma.eu/projects/2004/seattlecentral-library/

OMA 2009. TAIPEI PERFORMING ARTS CENTRE http://www.oma.eu/projects/ 2009/taipei-performing-arts-centre/

Stamp, J. 2012. The Unbuilt High-rise Designs of Rem Koolhaas and OMA. http://www.smithsonianmag.com/arts-culture/the-unbuilt-high-rise designs-of rem-koolhaas-and-oma-31406521/?no ist=\&onsite_source $=$ relatedarticles

Yoshida, N. 2006. OMA - SEOUL NATIONAL UNIVERSITY MUSEUM. Japan Architecture and Urbanism, 432, 40-51. 